\title{
TURISMO SUSTENTÁVEL E RIQUEZA SOCIAL: BASES PARA O DESENVOLVIMENTO DA ECONOMIA LOCAL
}

\section{SUSTAINABLE TOURISM AND SOCIAL WEALTH: BASES FOR THE}

DEVELOPMENT OF THE LOCAL ECONOMY

\section{Flávio dos Santos Oliveira}

Pós-Doutorado Fapes/Profix (2017-2018). Ganhador da Scholarship for Young Scholar (2018) pela Associazione Italiana per la Storia dell Economia Politica (STOREP). Ganhador do Prêmio Young Scholar (2017) pela Asociación Latinoamericana de Historia del Pensamiento Económico (ALAHPE). Tem experiência nas áreas de História, Filosofia, Sociologia e Economia, com especial destaque para História das Ideas Políticas, História da Filosofia, História Econômica e História do Pensamento Econômico.

E-mail: flaviosantosoliveira2@gmail.com. 


\section{RESUMO}

O artigo examina mudanças na concepção de turismo, tomando como ponto de partida questões de natureza econômica, social, política e ambiental. Ressaltam-se, em seguida, os benefícios e proventos advindos do fomento ao turismo, concedendo especial atenção ao seu efeito multiplicador. Subsequentemente, experiências bem-sucedidas da atuação do Estado em favor do turismo ganham evidência. Por fim, analisa-se o caso da Barra do Jucu, Vila Velha (ES), buscando-se extrair de seu exemplo proposições práticas para incrementar esta atividade de forma sustentável em âmbito local. A pesquisa foi concebida com base na metodologia de inventário da oferta turística do Ministério do Turismo, bem como em referências bibliográficas nacional e internacional sobre o tema. Os resultados obtidos indicam potencialidade turística relativamente baixa, tendo em vista as deficiências aí apresentadas.

Palavras-chave: Turismo. Plano Nacional de Turismo. Desenvolvimento. Cultura. Barra do Jucu.

\section{ABSTRACT}

The article examines changes in the conception of tourism, taking as a starting point issues of economic, social, political and environmental nature. The benefits and profits arising from the promotion of tourism are emphasized, drawing special attention to its multiplier effect. Subsequently, successful experiences of state action in favor of tourism are put into evidence. Finally, it analyzes the case of Barra do Jucu, Vila Velha (ES), seeking to extract from its example practical propositions to increase this activity in a sustainable way at the local level. The research was conceived based on the methodology of inventory of the tourism provided by the Ministry of Tourism, as well as in national and international bibliographical references on the subject. The results indicate a relatively low tourism potential, given the deficiencies presented there.

Keywords: Tourism. National Tourism Plan. Development. Culture. Barra do Jucu. 


\section{INTRODUÇÃO}

Nas últimas décadas, o turismo tem se revelado importante vetor de desenvolvimento, graças, sobretudo, a sua peculiar capacidade de geração de renda, receita pública, emprego e atração de investimentos. De acordo com o Ministério do Turismo (MT), em 2017, o setor turístico movimentou 7,6 trilhões de dólares, o equivalente a 10\% de toda a riqueza produzida em âmbito mundial. No Brasil, em 2016, o turismo foi responsável pela criação de mais de 7 milhões empregos, contribuindo no total com 152,2 bilhões de dólares, cerca de 8,5\% do PIB Nacional (BRASIL, PLANO NACIONAL DE TURISMO, 201822). Decerto, devido à natureza dos bens e serviços ofertados, a indústria turística se caracteriza não apenas por demandar menor capital para a geração de postos de trabalho, mas também por estimular direta ou indiretamente inúmeras outras atividades econômicas. ${ }^{1}$

0 artigo questiona, entretanto, em que medida o efeito multiplicador do turismo põe, de fato, em movimento as forças produtivas nacionais, já que há situações em que grandes somas de divisas são remetidas ao exterior como consequência de o capital externo, em muitos casos, ser a principal fonte de investimento no turismo. Indaga-se, outrossim, se a rentabilidade do turismo internacional corresponde, deveras, a alternativa plausivel de incremento das reservas cambiais, ao considerar o fato de o Brasil se localizar distante dos principais blocos emissores. Posteriormente, fundamenta-se a importância do Estado no que concerne à elaboração de políticas públicas voltadas para o turismo, com foco não apenas na legislação, mas também na criação de uma infraestrutura propícia para seu desenvolvimento.

Uma vez que o artigo coloca em evidência o potencial turístico de uma determinada localidade, a formulação e utilização de um instrumental analítico fazem-se necessários. Nesse sentido, a definição dos atrativos, equipamentos, serviços turísticos e infraestrutura de apoio, bem como suas respectivas categorias de análise, foram concebidas com base na metodologia de inventário da oferta turística proposta pelo Ministério do Turismo, por tratar-se de um instrumento oficial, continuamente revisto e testado, com vistas à aplicação em todo território brasileiro. 0 debate teórico, por sua vez, tem a intenção

\footnotetext{
${ }^{1}$ Ao satisfazer as aspirações dos turistas, incrementam-se os negócios dos hotéis, locadoras de automóveis, transportes, lojas, espaços de entretenimento, produção de alimento etc. Tal fato propicia maior transferência do poder de compra dentro da economia, ao fazer com que o produto do gasto turístico escoe ao longo do tecido social. Tomada em conjunto, a receita criada no setor hoteleiro, por exemplo, é empregada não apenas para reabastecer o estoque de capital, mas também para adquirir bens e serviços que propiciem a reparação de sua infraestrutura. Outra porção da renda, todavia, destina-se ao pagamento dos credores, aos salários dos funcionários; aos impostos, taxas etc. Em outros termos, uma parte dos proventos aciona a economia nacional, enquanto outra parte socializa a riqueza e aumenta a arrecadação do Estado.
} 
de apresentar um panorama holístico do turismo, de modo que este seja compreendido como um todo, capaz de abarcar muitas atividades ao mesmo tempo.

$\mathrm{O}$ artigo foi dividido, pois, em quatro seções. A primeira propõe uma breve exposição histórica sobre a atividade turística. Em seguida, detalham-se as vantagens, sobretudo econômicas, decorrentes do fomento ao turismo. Questões relativas às funções precípuas do governo quanto às políticas de turismo, bem como sua cabal aplicação, são discutidas na terceira seção. Por fim, propõem-se medidas para estimular o turismo sustentável de base local, considerando o caso da Barra do Jucu, Vila Velha, Espírito Santo. A pesquisa foi elaborada com base no conhecimento obtido pelo autor através de visitas in loco, mediante utilização de dados secundários obtidos em guias turísticos, publicações especializadas e sites de internet etc.

\section{EXPOSIÇÃO HISTÓRICO-ANALÍTICA DO CONCEITO DE TURISMO}

Não há consenso entre os estudiosos acerca da origem do termo turismo. Alguns derivam sua etimologia da expressão francesa tournée; outros relacionam-no ao vocábulo inglês turn. O que se sabe ao certo é que o ato de viajar tem acompanhado a experiência humana desde tempos remotos. No Egito, Grécia e Roma encontram-se relatos da existência de hotéis para hospedar comerciantes estrangeiros. Nos tempos modernos, a opulência e o esplendor de cidades italianas como Florença, Siena, Gênova, Veneza e outras, transformaram-nas em núcleos de intensa atividade comercial e de circulação de ideias, atraindo artistas e eruditos de diferentes partes da Europa, fascinados pela atmosfera intelectual e pela riqueza cultural ali em voga.

No limiar do século XVII, denominava-se Grand Tour a viagem realizada por nobres e dignitários de setores seletos da sociedade com fins, sobretudo, educativos. Nos séculos seguintes, jovens aristocratas e, posteriormente, burgueses completavam sua formação no exterior, auferindo com isso aquela distinção reservada às classes abastadas, dos artistas e hommes de lettres. 0 elemento novo introduzido por tal empreendimento se localiza no fato da viagem, o itinerário, bem como as principais atrações turísticas serem previamente organizadas. Mais tarde, o Grand Tour foi progressivamente substituído por outras formas de viagem, embora permanecesse seu caráter acentuadamente elitista (ROMITA, 2000, p. 7; ANDRADE, 2000, p. 9).

Não obstante as mudanças sociais advindas da industrialização, o turismo, por um bom tempo, restringiu-se a uma minoria. Admite-se, por isso, que a redução da jornada de trabalho e o reconhecimento de férias remuneradas foram determinantes para o crescimento do turismo. Outro fator decisivo para a expansão do setor turístico foi o advento de modernos e revolucionários meios de transportes. As ferrovias 
tornaram mais confortáveis as viagens, ao passo que modernos navios a vapor interconectaram diferentes continentes, reduzindo o tempo de viagem e favorecendo o deslocamento de grandes contingentes humanos² (ROMITA, 2000, p. 3; LICKORISH; JENKINS, 1997, p. 15).

Até a Primeira Guerra Mundial (1914 - 1918), o turismo cresceu notavelmente, o que despertou a atenção dos estudiosos. Em 1910, o economista austríaco Herman Von Schullard definia o turismo como "[...] a soma das operações, especialmente as de natureza econômica, diretamente relacionadas com a entrada, a permanência e o deslocamento de estrangeiros para dentro e para fora de um país, cidade ou região". Arthur Bormann, por outro lado, definiu-o como: "[...] o conjunto de viagens que tem por objetivo o prazer ou motivos comerciais, profissionais ou outros análogos, durante os quais é temporária sua ausência da residência habitual". Na década de 1940, Walter Hunziker e Kurt Kraft ampliaram o conceito de turismo ao defini-lo como "[...] o conjunto das inter-relações e dos fenômenos que se produzem como consequência das viagens e das estadias de estrangeiros, sempre que delas não resultem um assentamento permanente, nem que eles se vinculem a alguma atividade produtiva".3 (GILBERT, 2004, p. 49-50; FERREIRA, 2007, p. 31).

A partir de 1950, o turismo desenvolveu-se de forma intensa, fato que evidencia a conjugação de diversos fatores, incluindo a garantia de direitos sociais, como férias remuneradas e maior disponibilidade de tempo para lazer; o desenvolvimento do transporte aéreo; o surgimento dos grandes conglomerados de operadoras e agências de turismo, que ampliaram a oferta de pacotes de viagem etc. Até então, o turismo constituía-se como atividade fragmentada, em que hotéis, agências de viagens, operadores de turismo e de transporte trabalhavam, em geral, independentemente um do outro. Doravante, no entanto,

\footnotetext{
2 Thomas Coock (1808-1892) foi um empresário inglês que vislumbrou oportunidades de negócios nestes novos meios de transportes. Em 1841, ele apresentou o primeiro pacote turístico, embora companhias ferroviárias também oferecessem viagens de excursão. Em 1844, viajaram 360.000 passageiros em trens de excursão; sete anos depois, as cifras eram de 774.910, números que foram acrescidos em seguida. A novidade trazida por Cook, todavia, encontra-se em sua ideia original de organizar toda a viagem - transporte, acomodação, atividades ou visitas a um lugar desejado etc., oferecendo um verdadeiro produto turístico. Em 1851, Coock levou 165.000 excursionistas de Yorkshire ao Great Exhibition e, logo depois, em 1856 e 1865, organizou respectivamente o primeiro tour ao continente europeu e aos Estados Unidos. O bom êxito de Cook foi seguido por outros empreendendores do setor de transportes, expandindo, assim, a prestação de serviços turísticos para atender aos anseios de um público cada vez mais variado (LICKORISH; JENKINS, 1997, p. 17-19).

${ }^{3}$ É interessante notar que, em 1937, um comitê de especialistas da Liga das Nações definiu o turista como "aquele que viaja por um período de 24 horas ou mais em um país diferente daquele em que geralmente reside". Ainda incluíam nessa categoria pessoas que viajam a negócio, bem como em busca de prazer, cuidados de saúde ou razões familiares. Essa definição estabeleceu, outrossim, que as pessoas que chegassem a um destino por um período inferior a 24 horas deviam ser classificadas como excursionistas (GILBERT, 2004, p. 50).
} 
o turismo abandonou este aspecto segmentário, tornando-se atividade cada vez mais sistêmica, que integra uma gama de produtores e fornecedores de diferentes tipos de bens e serviços, e que, apesar de se apresentarem separadamente, configuram-se um todo articulado. ${ }^{4}$ Por outro lado, as elevadas taxas de crescimento econômico, resultantes da expansão industrial dos países desenvolvidos, juntamente com a crescente participação dos salários na renda, foram decisivas para o desencadeamento do que se convencionou chamar turismo de massa (LICKORISH; JENKINS, 1997, p. 3-13; BEZERRA, 2006, p. 347349; SANTOS, 2010, p. 13-25).

Na década de 1960, a ascensão da classe média nas nações industrializadas foi vista como oportunidade pelos países do Terceiro Mundo para estimular seu crescimento por meio do turismo. Seus climas ensolarados e suas belezas naturais tornaram-se o epicentro de intenso roteiro turístico. Tal fato provocou, por sua vez, um corte epistemológico no estudo do turismo. Até então, grande parte dos estudos ocupava-se da medição dos benefícios econômicos, sendo pouca atenção concedida a uma característica fundamental inerente à viagem, a saber, o contato e a interação entre os turistas e a comunidade local, bem como os efeitos socioculturais advindos desse relacionamento (LICKORISH; JENKINS, 1997, p. 77; KADT, 1979, p. 34).

Tornou-se evidente que, quando turistas visitam uma determinada comunidade, eles trazem consigo não apenas seu poder de compra, mas também um outro modus vivendi, um tipo diferente de comportamento, que pode transformar profundamente os costumes locais, removendo ou alterando os hábitos e instituições que constituem o arcabouço cultural da população hospedeira. O contato com o estrangeiro pode, ademais, produzir aculturação das populações anfitriãs devido à ação do "efeito mimético", ou seja, a atitude psicossocial que exprime uma inclinação dos nativos de uma comunidade isolada a copiar hábitos estranhos a sua cultura quando do contato reiterado com estrangeiros. O problema é que, em muitos casos, quando não satisfeitas essas aspirações, tais anseios amiúde redundam em

\footnotetext{
${ }^{4}$ A Segunda Guerra Mundial (1939-1945) foi celeiro de revolucionárias inovações nas áreas de transporte e comunicação. Os anos que se seguiram testemunharam a rentabilização desses progressos tecnológicos. O setor turístico beneficiou-se significativamente disso. A conversão de aeronaves militares para vôos civis criou condições propícias para o desenvolvimento de serviços de vôos fretados. As inovações tecnológicas subseqüentes, como a introdução do propulsor a jato, garantiram uma redução contínua nos preços dos transportes, aumentando a oferta de viagens intercontinentais, o que explica o notável crescimento dos negócios relacionados à cadeia hoteleira, bem como o crescimento das operadoras turísticas e agências de viagens, seguradoras, locadoras de automóveis etc. (BEZERRA, 2006, p. 349).
} 
tremenda frustração ou levam ao esmorecimento moral, mendicância, prostituição e perda de dignidade, gerando custos sociais irreversiveis. ${ }^{5}$ (FERREIRA, 2007, p. 68-69; LICKORISH; JENKINS, 1997, p. 78-79).

Por causa disso, em 1980, foi realizada em Manila, Filipina, uma conferência promovida pela Organização Mundial do Turismo, em que foram reunidas as delegações de 107 Estados para discutir como desenvolver o turismo responsável, considerando-o não mais como atividade puramente econômica. Com o estreitamento das relações pacíficas entre as duas grandes potências (EUA e URSS), tornou-se evidente que o turismo não apenas poderia ajudar a suprimir o abismo econômico entre países desenvolvidos e subdesenvolvidos, mas também poderia desempenhar papel indispensável na promoção da paz mundial. Tal constatação levou ao reconhecimento da necessidade de assegurar a harmonia e o desenvolvimento sustentável do turismo. ${ }^{6}$

Com efeito, diferentemente do que se verificava até então, o turismo sustentável foi definido como "aquele que atende às necessidades dos turistas de hoje e das regiões receptoras, ao mesmo tempo em que protege e amplia as oportunidades para o futuro". Sua prioridade máxima consiste em (i) proteger, preservar e intensificar o uso esclarecido dos recursos naturais, incluindo o cuidado para com a biodiversidade; (ii) estimular a melhoria da qualidade do meio ambiente físico disponível para os residentes; (iii) proporcionar

\footnotetext{
${ }^{5}$ Além das questões relacionadas à perda do estímulo pelas atividades tradicionais, bem como os efeitos danosos da sazonalidade, outro grave problema identificado no turismo de massa refere à degradação do meio ambiente. Decerto, se por um lado o turismo pode ser um fator de desenvolvimento econômico, por outro, se desprovido de planejamento adequado, ele pode ter efeitos destrutivos tanto sobre a biodiversidade, quanto sobre as comunidades primitivas, como consequência do uso indevido de recursos naturais: água potável, terra, florestas, vida marinha etc. Em muitos casos, o turismo pode exercer enorme pressão sobre uma área e levar a impactos como erosão do solo, aumento da poluição, perda de habitat natural, aumento da pressão sobre espécies ameaçadas e maior vulnerabilidade a incêndios florestais, forçando as populações locais a competir pelo uso de recursos críticos (RABBANY; AFRIN; RAHMAN; ISLAN; HOQUE, 2013, p. 117-118).

${ }^{6}$ Nesse ínterim, ganha notoriedade a ideia de que é possivel promover desenvolvimento sem, no entanto, privar as gerações presente e futura do acesso aos recursos naturais necessários à manutenção da vida. Em 1987, a Comissão Mundial sobre o Meio Ambiente e desenvolvimento publicou o Relatório Brundtland, o qual definiu desenvolvimento sustentável como aquele que "atende às necessidades do presente sem prejudicar a capacidade das gerações futuras de atender as suas necessidades". Em 1992, citando caso parecido, foi realizada no Rio de Janeiro a Conferência das Nações Unidas sobre Ambiente e Desenvolvimento, que reforçou os preceitos supracitados ao institucionalizar o entendimento de que é necessário conciliar a proteção ambiental, o desenvolvimento econômico e o combate à pobreza de maneira sustentável (HANAl, 2012, p. 201).
} 
justificativa econômica e meios para a regeneração do meio ambiente deteriorado ou em desuso, com base em heranças culturais e socioeconômicas, buscando salvaguardar os costumes e tradições locais. ${ }^{7}$

o Código Global da Ética do Turismo, documento compilado em 2001, sob a chancela da Organização Mundial do Turismo, estabelece que minimizar o impacto negativo do turismo tanto sobre o meio ambiente, quanto sobre a herança cultural local constitui um dos seus mais elevados objetivos. ${ }^{8}$ Nesse sentido, ficou instituído o respeito às tradições sociais e práticas culturais de todos os povos, de sorte que os turistas e visitantes devem abster-se de atitudes ofensivas ou injuriosas para com as populações locais, ou igualmente provocar danos ao meio ambiente. Do mesmo modo, infraestrutura e atividades turísticas deveriam ser planejadas de tal forma que protegessem a herança natural, composta de ecossistemas e biodiversidade, a fim de preservar a vida silvestre ameaçada. Desde então, as políticas de turismo devem ser conduzidas considerando não apenas a preservação do patrimônio estético, artístico e arqueológico, destinando parte dos ganhos da atividade turística à manutenção, proteção, desenvolvimento e embelezamento dessa área, mas também permitindo que a cultura, o artesanato e o folclore sobrevivam e floresçam, de modo que as populações locais compartilhem dos benefícios econômicos e sociais gerados pelo turismo, aumentando-Ihes o padrão de vida por meio da criação de emprego e desenvolvimento para essas localidades.

\section{TURISMO E O VIÉS DESENVOLVIMENTISTA}

De modo sumário, o turismo consiste no movimento temporário de pessoas a destinos fora de seu entorno habitual por período superior a um dia, e inferior a um ano, para fins de recreação, lazer, negócios etc. Compreende, desse modo, um conjunto de operações, equipamentos e serviços (agenciamento, transporte, hospedagem, alimentação, entretenimento etc.), que são disponibilizados para a realização de uma viagem, que pode ser de âmbito local, regional, nacional ou internacional. De modo geral, viajantes são consumidores de serviços turísticos, quaisquer que sejam as motivações. No entanto, de acordo com a Organização Mundial do Turismo (OMT), esses consumidores podem ser classificados em turistas,

\footnotetext{
A supracitada Declaração de Manila proclama que: "A satisfação das exigências do turismo não deve ser prejudicial aos interesses sociais e econômicos da população em áreas turísticas, ao meio ambiente ou, acima de tudo, aos recursos naturais, locais históricos e culturais, que são a atração fundamental do turismo. Todos os recursos turísticos são parte da herança da humanidade. As comunidades nacional e internacional devem tomar as medidas necessárias para garantir a sua preservação. A conservação de sítios históricos, culturais e religiosos representa, em todos os momentos, e especialmente em tempos de conflito, uma das responsabilidades fundamentais dos Estados".
}

${ }^{8}$ Disponível em: <http://cf.cdn.unwto.org/sites/all/files/docpdf/gcetbrochureglobalcodeen.pdf>. >. Acesso em: 11 nov. 2018. 
aqueles que sojornam em uma determinada localidade por um lapso superior a 24 horas, ao passo que excursionistas e visitantes são aqueles cuja visitação não excede 24 horas. ${ }^{9}$ (OMT, 1994; BRASIL, 2010a).

De um ponto de vista estritamente econômico, quatro são os elementos que constituem o mercado turístico: oferta, demanda, destinação turística e operações de mercado. Visto que o turismo pressupõe deslocamento e motivação, a oferta turística representa uma vasta gama de atrativos, produtos e serviços colocados à disposição dos turistas e visitantes a fim de satisfazer-lhes as aspirações, desfrute e consumo. ${ }^{10}$ Por outro lado, entende-se por demanda turística o conjunto de bens e serviços requeridos por um grupo bastante heterogêneo de viajantes, a determinado preço, qualidade, período de tempo e local, considerando-se, ainda, a disponibilidade de renda, as épocas de alta e baixa estações, bem como as diferentes taxas cambiais, no que toca a viagens internacionais. O espaço geográfico ou destinação turística, por seu turno, concerne não apenas aos recursos e ambientes naturais (clima, flora, fauna, relevo, praias e outros atrativos existentes), mas também o lugar onde a conjunção entre a oferta e a demanda se realiza. Por fim, os operadores do mercado turístico são as agências de viagens, companhias de transporte e instituições públicas e privadas, cuja principal função é atuar na qualidade de intermediários entre viajantes e fornecedores de produtos e serviços turísticos, mediante a criação de pacotes, ofertas, controle de preços etc. (OMT, 2001; BRASIL, 2010b, p. 15-55; 2007, p. 15; LICKORISH; JENKINS, 1997, p. 63).

Nota-se que, segundo o panorama microeconômico, a atividade turística constitui uma complexa cadeia produtiva em que diversos setores cooperam entre si para a satisfação do turista. Essa interdependência caracteriza o fenômeno econômico denominado efeito multiplicador, o qual define o processo espontâneo de distribuição de renda, decorrente da sucessão de despesas que tem origem no gasto do turista, e que beneficia outros empreendimentos relacionados direta ou indiretamente ao turismo. Tal favorável circunstância se explica pelo fato de qualquer aumento na demanda de bens e serviços produzidos para contentamento dos turistas produz incremento na demanda de bens e serviços procedentes de outros negócios, como hotéis, locadoras de carros, restaurantes, empresas de transporte,

\footnotetext{
9 São inseridos ainda nestas últimas categorias: a tripulação de barcos e aviões em reparação ou que fazem escala em país estrangeiro, mas que utilizam os meios de alojamento disponíveis; pessoas que chegam a um país a bordo de um navio de cruzeiro, e que estão alojados a bordo da embarcação, ainda que desembarquem para realizar visitas de um ou mais dias de duração; e, por fim, aqueles que não abandonam a área de trânsito do aeroporto ou do porto em que se encontram.

10 São, outrossim, fatores decisivos à profícua configuração da oferta turística: a disponibilidade de serviços públicos como postos de saúde, fornecimento de água, redes de telecomunicação e distribuição de energia; a existência de uma infraestrutura básica (estradas, meios de hospedagens, restaurantes, caixas eletrônicos etc.), que viabilize o acesso e o usufruto da destinação turística. Além disso, a gestão, o marketing e o preço são elementos que exercem significativa influência na apresentação do produto turístico (BRASIL, 2010a, p. 24-25; FERREIRA, 2007, p. 90).
} 
lojas, espaços de entretenimento etc. Isso pode ser verificado na mudança nos níveis reais de produção, emprego, renda e receita pública que é gerada na economia como consequência de um aumento nos gastos do turista. Além disso, o melhoramento da infraestrutura básica existente nas destinações turísticas amplia a oferta de empregos, do mesmo modo que a crescente demanda por alimentos nessas localidades acresce a produção agrícola (FERREIRA, 2007, p. 61; LICKORISH; JENKINS, 1997, p. 67-68; SILVA, 2004, p. 31-36).

Os ganhos advindos do efeito multiplicador do turismo variam, no entanto, segundo o volume de mercadorias e serviços importados para o consumo dos viajantes; a inclinação dos residentes a usar produtos nacionais, bem como sua propensão à parcimônia. Em geral, constata-se que, quanto menos desenvolvida for uma economia, parcela bem maior dos proventos oriundos do gasto turístico destina-se para outras regiões, o que produz baixo multiplicador de renda e emprego. Se a atividade turística for sustentada, por exemplo, pelo capital externo, na forma de financiamentos originados de organismos internacionais ou de investimentos por parte de empresas multinacionais, parcela expressiva da renda proveniente da atividade turística será transferida para o exterior, sobrando para a comunidade local o montante recolhido por meio de impostos e salários, o que não representa benefícios significativos (SILVA, 2004, p. 35).

Sob o prisma macroeconômico, o mercado turístico internacional tem auferido cada vez mais importância nas políticas de turismo dos países em desenvolvimento, graças, entre outras, à sua capacidade de aumentar as reservas cambiais. De fato, tendo em conta variáveis como os níveis de inflação, as taxas de lucro e de câmbio, os turistas estrangeiros, em geral, tendem a dispor de maior poder de compra, se comparados com os turistas domésticos que, devido às elevadas taxas de inflação e juros vigorantes, sobretudo, em muitos países emergentes, tendem a sentir-se menos inclinados a viajar e, por isso, produzem, em muitos casos, receita economicamente irrisória. Por outro lado, em países como Estados Unidos, Alemanha, Japão e outros, o turismo internacional se afigura como importante fator de equilíbrio monetário, ao dar vazão ao excedente de capital de seus conterrâneos, quer mediante estímulo a viagens ao exterior, quer por meio de investimentos na cadeia produtiva do turismo de outros países, o que impacta não apenas as atividades comerciais, mas também contribui para a redistribuição da riqueza mundial (TAMBAKTIS, 2016, p. 9; LICKORISH; JENKINS, 1997, p. 53; BALAIA; PETRUSCU, 2011, p. 217-218).

Entende-se por receita de câmbio originária do turismo a aquisição de moedas não nacionais obtidas pela venda de bens e serviços a turistas estrangeiros. Como se sabe, o valor de uma moeda é expresso em sua taxa de câmbio, isto é, o valor de uma unidade de moeda em relação a uma unidade de outra; por exemplo, a paridade libra/dólar. Por causa disso, muitos governos de países emergentes encorajam o turismo internacional, pois os turistas oriundos dos principais países emissores, em geral, levam a termo relações comerciais no exterior por meio de moedas fortes, ou seja, aquelas que são livremente conversiveis 
e aceitas internacionalmente, já que são emitidas pelos países economicamente mais avançados. ${ }^{11}$ Em 2010, estudos divulgados pela United Nations Conference on Trade and Development sugerem ser o turismo a principal fonte de ganhos em divisas para um terço dos países em desenvolvimento e metade dos países menos desenvolvidos (UNCTAD, 2010). No caso do Brasil, por exemplo, o Plano Nacional de Turismo (2018-22) prevê alcançar, até 2022, resultados como o aumento da chegada de estrangeiros de 6,6 milhões para 12 milhões e a ampliação da receita cambial do turismo dos atuais US\$ 6,6 bilhões para US\$ 19 bilhões $^{12}$ (LICKORISH; JENKINS, 1997, p. 66; AKTAR; SADEKIN; SAHA, 2014, p. 162-163).

Tal aspiração, contudo, implica colocar em evidência o fator geográfico como variável importante na determinação do fluxo turístico. Em 2017, o turismo mundial atingiu 1,3 bilhão de viajantes internacionais, o que representa um incremento de 7\% com relação a 2016. Esse crescimento foi percebido não apenas nos vários destinos que vinham se destacando nos últimos anos, mas também em outros que se recuperaram das quedas sofridas em anos anteriores. A Europa, com os destinos mediterrâneos na liderança, registrou acréscimo de 8\% em relação ao ano anterior, alcançando cifras iguais ao continente africano, que consolidou a recuperação iniciada em 2016. Em contrapartida, a Ásia e o Pacífico contabilizaram 6\% de turistas a mais, e o Oriente Médio, 5\%. Já as Américas receberam 207 milhões de turistas internacionais, crescimento equivalente a 3\%, sendo que América do Sul obteve o melhor resultado, seguido por América Central e Caribe. Na América do Norte, bons resultados localizam-se no México e Canadá, o que contrasta com uma diminuição nos Estados Unidos, o maior destino da região. (OMT, 2018; BRASIL, PNT, 2018, p. 31).

De acordo com Márcia Maria de Oliveira Bezerra, os grandes países emissores podem ser agrupados, segundo a localização geográfica, em três grandes blocos, distribuídos por três continentes: o primeiro, o da América anglo-saxônica, congrega Estados Unidos e Canadá; o segundo, o Bloco Europeu, incluindo a Rússia; e o terceiro, o Bloco Oriental, que incorpora a Austrália. A célebre autora ainda ressalta que estar nesse conjunto parece contar favoravelmente para tornar esse país um grande receptor. Assim, o México tem o bloco EUA-Canadá como o seu principal mercado. Portugal, Turquia, Grécia, República Tcheca e Egito atraem os turistas estrangeiros dos países europeus que são seus grandes demandantes.

\footnotetext{
${ }^{11}$ Quanto aos países que mais gastam em turismo, os Estados Unidos e a Alemanha ocupam o primeiro lugar. Estes dois países, juntamente com o Japão, produzem mais de um quarto das receitas internacionais do turismo em todo o mundo e, juntamente com o Reino Unido, a Itália e a França, produzem quase metade do total das receitas turísticas mundiais (BEZERRA, 2006, p. 364).

12 No Brasil, a participação direta do turismo na economia foi de US\$56,8 bilhões em 2016, o equivalente a 3,2\% do PIB. Já a contribuição total do setor foi de US\$ 152,2 bilhões, 8,5\% do PIB Nacional. Quanto ao nível de emprego no país, o setor gerou mais de 7 milhões de postos de trabalho, o que representou 7,8\% do emprego total. A World Travel \& Tourism Council (WTTC) estima um crescimento de 3,3\% até 2027, chegando à contribuição total do setor na economia em 9,1\% do PIB, o equivalente a US\$ 212,1 bilhões (BRASIL, PNT, 2018, p. 26).
} 
Ao passo que, os países localizados na Ásia, como Hong Kong, Tailândia, Indonésia e Cingapura têm entre seus visitantes estrangeiros principalmente os turistas procedentes do Bloco Oriental. O Brasil, por uma questão, sobretudo, espacial, no que se refere à demanda turística externa, tende a ser relativamente pouco procurado por turistas estrangeiros provenientes dos blocos emissores acima mencionados ${ }^{13}$ (BEZERRA, 2006, p. 364-365).

A Embratur, nos últimos anos, reconheceu que o Brasil não teria condições de competir com os destinos turísticos mais próximos da Europa e Estados Unidos. Por isso, tem ampliado seu foco de propaganda externa principalmente para os países sul-americanos. Contudo, em função das características desse mercado, parece razoável supor que, a curto prazo, o Brasil continuará a ter baixa inserção no mercado turístico internacional. Por outro lado, no mercado doméstico, de acordo com as análises da Organização Mundial do Turismo, calcula-se que o turismo interno seja dez vezes maior que o volume do turismo internacional. Por conseguinte, uma que distúrbios políticos, mudança na paridade entre moedas internacionais e fenômenos climatológicos não previsíveis são exemplos de influências externas que, juntamente com a sazonalidade, atribuem ao turismo alto grau de incerteza quanto ao seu desempenho global, uma boa parte dos esforços do Ministério do Turismo tem sido direcionado ao fomento do turismo local, regional e nacional (BEZERRA, 2006, p. 370; SILVA, 2004, p. 32; BRASIL, PNT 2018, p. 36).

\section{ESTADO E POLÍTICAS PÚBLICAS DE INCENTIVO AO TURISMO}

Embora o setor privado desempenhe papel importante no fomento ao turismo, a experiência tem mostrado ser imprescindivel, sobretudo nos países emergentes, a participação direta do governo não apenas na elaboração de políticas públicas e de um plano nacional de turismo, mas também na provisão de instalações, serviços de hospedagem e fundos para financiamento nos níveis nacional, regional e local. Além disso, compete ao Estado restringir a competição injusta entre os prestadores de serviços turísticos, aumentar a demanda, melhorar a qualidade do produto turístico, bem como a sua divulgação tanto

\footnotetext{
${ }^{13}$ A ilustre estudiosa define como "longe dos grandes blocos emissores" o país que esteja fisicamente distante, não partilhe de traços históricos comuns e que, por esse motivo, não conta com uma demanda turística estrangeira suficiente para estimular o crescimento da oferta turística em seu território (BEZERRA, 2006, p. 369).
} 
nos mercados nacionais, quanto no exterior. ${ }^{14}$ Ainda assiste ao governo formular a política de impostos aplicada direta e indiretamente à atividade turística, assim como avaliar os recursos disponíveis, a fim de determinar como eles devem ser melhor empregados na construção de edifícios, equipamentos, redes de comunicação, parques, playgrounds, museus etc. (BALAIA; PETRUSCU, 2011, p. 217- 218; NAWAZ; HASSAN, 2016, p. 581-582).

Ao contrário da concepção liberal clássica, que considera invasiva a intervenção do Estado nos assuntos econômicos, no caso do turismo tal interferência se mostra conveniente. Investimentos públicos ou sem fins lucrativos reduzem, por exemplo, riscos para o setor privado, ajudam a assegurar a rentabilidade do projeto, bem como o retorno do capital empregado. Em alguns casos, o setor público é requisitado para financiar os custos associados tanto à comodidade turística, quanto às instalações relacionadas a isso. Casos recentes de países em que o turismo evoluiu e floresceu como importante atividade econômica, como Bahamas, Jamaica, México, Quênia, Marrocos, Tunísia, Egito e Indonésia, o envolvimento direto e o investimento dos governos desempenharam papel crucial no fortalecimento do setor. Ademais, uma vez que o turismo é um empreendimento econômico de alto risco, a maioria dos investidores privados pode não estar disposto a aplicar seu dinheiro em novos destinos turísticos em fase exploratória ou que não garantem ganhos compativeis ao capital empregado (BALAIA; PETRUSCU, 2011, p. 218; NAWAZ; HASSAN, 2016, p. 583).

Estudo conduzido pela Organização Mundial do Turismo (1996) apregoa que o governo cumpre papel substancial nas fases iniciais de fomento ao turismo, pois enormes investimentos são requeridos para provisão de facilidades e infraestrutura básica, o que inibe investidores do setor privado assumir sozinhos os riscos até que um clima de confiança seja estabelecido. Convém, portanto, que, a princípio, autoridades públicas em níveis nacional, regional e local assumam a responsabilidade de planejar, promover e efetivamente implementar políticas voltadas para o desenvolvimento do turismo. Como ressalta Bezerra, para entender o desenvolvimento do turismo de massa é importante considerar o papel dos governos, pois em diversos países, inclusive europeus, foram implementados planos para favorecer sua expansão, dentro de um processo de planejamento setorial, de modo que, em muitos casos, "além de disporem sobre aspectos normativos do setor, tornaram-se responsáveis pela definição das políticas

\footnotetext{
${ }^{14}$ Entende-se por produto turístico a resultante composta por: (i) recursos naturais (clima, paisagens, fauna, flora, entre outras) e culturais (patrimônio arquitetônico, gastronomia, artesanato etc.); (ii) bens e serviços (produtos alimentícios, materiais esportivos e de entretenimento etc.); (iii) infraestrutura e equipamentos (meios de hospedagens, restaurantes, parques etc.). Também se inclui àquela categoria a gestão (como o produto é gerido e ofertado); (v) imagem da marca (como este produto é percebido pelos consumidores); e (vi) preço (o valor a ser pago por seu usufruto) (BRASIL, 2010a, p. 24; 2004, p. 11).
} 
turísticas domésticas e pela coordenação dos mecanismos de incentivo para desenvolvê-las" (NAWAZ; HASSAN, 2016, p. 584-586; BEZERRA, 2006, p. 351).

Dentre as medidas políticas estruturadas por países como Inglaterra, França, Grécia, Portugal, Noruega, Finlândia, México, entre outros, merece destaque a administração do crédito para reduzir o custo da implementação dos equipamentos turísticos em seus territórios, a concessão de financiamentos e, em alguns casos, garantias para a realização de empréstimos ao setor. "Os governos desses países costumavam conceder empréstimos a taxas de juros preferenciais para financiar os investimentos turísticos privados que estivessem afinados com as políticas governamentais para o setor". Na América Latina, é notável a concessão de incentivos fiscais como mecanismo de favorecimento setorial, embora o mesmo fosse comumente dirigido ao negócio hoteleiro e de infraestrutura (construção de estradas, aeroportos, abastecimento de água, sistemas de esgotos e saneamento, eletricidade e telecomunicações). A esse respeito, constata-se que, embora o Banco Mundial tenha emprestado recursos para pequenos países, como Belize e República Dominicana, foi o BID (Banco Interamericano de Desenvolvimento) que se destacou no financiamento da construção de infraestrutura turística em países como Brasil e México (BEZERRA, 2006, p. 352).

No Brasil, os debates e articulações políticas em favor do empreendimento turístico remonta à década de 1920, quando foi criada a Sociedade Brasileira de Turismo. A primeira menção legal a essa atividade econômica, no entanto, localiza-se no Decreto-Lei n $406 / 1938$, que normatiza a entrada de estrangeiros em território nacional, bem como restringe a venda de passagens, sobretudo aéreas e marítimas, às agências autorizadas pelo Ministério do Trabalho, Indústria e Comércio. Em 1940, o Decreto-lei n 2.440 formaliza as empresas e agências de turismo como estabelecimentos de assistência remunerada aos viajantes, exigindo-Ihes, todavia, prévio registro junto aos órgãos do governo. Nos anos 50, notável avanço pôde ser verificado com a criação do Departamento Nacional de Turismo e da Associação Brasileira de Agências de Viagem (ABAV). Nesse contexto, também é digno de menção o Decreto $n^{\circ}$. 44.863/1958, que instituiu, no governo de Juscelino Kubitschek, a COMBRATUR - Comissão Brasileira de Turismo -, órgão de consulta e execução em matéria de turismo, subordinada diretamente à presidência da República. ${ }^{15}$

\footnotetext{
15 No começo da década de 1950, a hotelaria nacional já era de razoável proporção e concentrava-se nas principais capitais do país. Do mesmo modo, as companhias aéreas aumentaram suas frotas, ao passo que as agências de viagens começaram a se organizar criando associações regionais e participando de eventos internacionais. A Confederação Nacional do Comércio, por seu turno, começou uma campanha para oficializar o turismo no país, iniciando suas atividades com a organização dos Congressos Brasileiros de Turismo, realizados em 1956 e 1957. "De sua iniciativa, foi criado o Conselho de Turismo da Confederação Nacional do Comercio (MÜLLER; HALLAL; RAMOS; GARCIA, 2011, p. 694).
} 
Desde então, o empresariado de grandes hotelarias, companhias de transportes e agenciadoras de viagens passaram a influenciar de forma decisiva os rumos das políticas públicas para o turismo. Em 1966, a Empresa Brasileira de Turismo (EMBRATUR) e o Conselho Nacional de Turismo (CNTUR) foram concebidos por meio do Decreto-lei $n^{\circ} 55$, com o objetivo de criar uma estrutura federal sistematizada, desenvolver políticas de incentivo ao turismo, coordenar a expansão de grandes empreendimentos de hospedagem e transporte aéreo, bem como padronizar os pacotes de viagem oferecidos por grandes operadoras de turismo. Em seguida, constituiu-se propósito irrevogável traçar diretrizes para implantar, efetivamente, o Sistema Nacional de Turismo, criado pelo Governo Federal, "estudando os aspectos de descentralização e as estratégias operacionais voltadas a coordenar os esforços oficiais em um só pensamento e orientação". Segundo Gladston Mamede, estímulo importante ao turismo brasileiro se consolida com a criação de fundos para o financiamento de projetos de desenvolvimento, a exemplo do FUNGETUR (Fundo Geral de Turismo - 1971) e do FISET (Fundo de Investimento Setorial de Turismo - 1974) (AGUIAR, 2010, p. 2-5; MÜLLER, HALLAL, RAMOS, GARCIA, 2011, p. 695; MAMEDE, 2004, p. 22).

No início da década de 1970, o Brasil vivia o chamado "milagre econômico brasileiro", período em que a economia do país experimentou crescimento acelerado, com taxas médias anuais superiores a 10\%, e redução nos índices de inflação, com média anual inferior a 20\%. Esse cenário atraiu muitos investimentos, tanto nacionais como estrangeiros, baseados nas perspectivas otimistas em relação à economia e aos negócios. Nesse período, o turismo foi visto como atividade econômica a impulsionar o desenvolvimento do país. Além disso, outros eventos como o surgimento dos primeiros cursos superiores de turismo e dos primeiros congressos científicos da área retratam uma década de grandes avanços, tanto privados quanto públicos, para a atividade turística brasileira. Estados e prefeituras passaram a oferecer vantagens fiscais para os investidores, como a redução de alíquotas nos impostos estaduais e municipais, enquanto o governo federal concedeu reduções de impostos como o IPI (Imposto sobre Produtos Industrializados) ${ }^{16}$ (MÜLLER; HALLAL; RAMOS; GARCIA, 2011, p. 696; AGUIAR, 2010, p. 8).

\footnotetext{
${ }^{16}$ Grande parte dos incentivos financeiros e fiscais concedidos pela EMBRATUR foi utilizado pela rede hoteleira. A legislação turística brasileira concedia deduções de até $50 \%$ do imposto de renda para pessoas jurídicas interessadas na construção, ampliação ou reforma de hotéis. Em função desses financiamentos e incentivos, as empresas hoteleiras nacionais praticamente dobraram sua capacidade, fazendo com que empresas internacionais se instalassem no Brasil. As principais cadeias nacionais criadas nesse período foram Hotel Nacional Rio, o Horsa, o Othon, o Eldorado e a rede Tropical de Hotéis. Em 1975 instalou-se em São Paulo a primeira cadeia hoteleira internacional, a Hilton, com 400 apartamentos, dotada de nova filosofia hoteleira e com modernos sistemas de gestão. Ainda nos anos 70, instalaram-se outras cadeias, como a Sheraton (1974), Holiday Inn (1975), Meridien (1975), Novotel (1976) e Club Mediterranée (1977) (MÜLLER; HALLAL; RAMOS; GARCIA, 2011, p. 696; AGUIAR, 2010, p. 8-9).
} 
No final da década de 1980, com a promulgação da nova Constituição, um novo modelo de Estado instaura-se no Brasil. É com base neste novo arcabouço jurídico, que a legislação do turismo começa a ser reinventada, respeitando princípios fundamentais como a preservação do meio ambiente, a defesa da livre iniciativa, a redução de desigualdades regionais, etc. ${ }^{17}$ De acordo com Tércio Ferraz, a Constituição exige do Estado, como agente normativo e regulador da atividade econômica, o exercício, na forma da lei, da função de fiscalização, visando ao funcionamento eficiente do mercado. Desde então, tem crescido em importância o papel do órgão estatal regulador para o setor turístico, hoje exercido pelo Ministério do Turismo, com o apoio do Conselho Nacional de Turismo (BRASIL, 2007a, p. 19). Com o advento da globalização, o crescimento do turismo no mundo e, particularmente, a expansão contínua da atividade no Brasil consolidam-no como importante fonte de geração de emprego e renda, o que tem se refletido nas políticas públicas direcionadas a essa atividade.

A Lei $n^{\circ}$ 11.771, de 17 de setembro de 2008, por exemplo, define o turismo como instrumento de desenvolvimento econômico e social, promoção da diversidade cultural e preservação da biodiversidade. De acordo com a Política Nacional de Turismo, o poder público, obedecendo aos princípios constitucionais da livre iniciativa e da descentralização, deve atuar, mediante apoio técnico, logístico e financeiro, na consolidação do turismo como importante fator de conservação do patrimônio natural e cultural brasileiro, promovendo não apenas desenvolvimento sustentável, distribuição de renda e redução das disparidades sociais e econômicas de ordem regional, mas tambémenvolvendo efetivamente as comunidades receptoras nos benefícios advindos da atividade econômica. A Lei ainda preconiza a ampliação dos fluxos turísticos, a promoção e o aprimoramento do produto turístico brasileiro; o estímulo à criação, à consolidação e à difusão dos produtos e destinos turísticos nacionais, tendo em vista beneficiar, principalmente, as regiões de menor nível de desenvolvimento econômico e social, mediante o incentivo à criação de organismos autônomos e de leis facilitadoras para o fortalecimento do setor.

\footnotetext{
17 A previsão constitucional do respeito à livre concorrência dentro do ordenamento jurídico brasileiro tem sido erroneamente avaliada como a prescrição de ausência de ingerência estatal, quando na verdade representa justamente o oposto. A doutrina de direito econômico e sobretudo de direito antitruste, ao mesmo tempo que preconiza o princípio da livre concorrência, evidencia a necessidade de regulamentação das atividades econômicas, para que a concorrência possa ser preservada. De certo, a idéia de uma disputa desregrada não procede da experiência histórica. Para que uma concorrência salutar exista, o mercado reclama por uma atuação estatal, capaz de estabelecer limites e coibir os abusos. É desse modo que deve ser interpretada a livre concorrência, prevista no artigo 170, IV da Constituição Federal de 1988, isto é, em conjunto, com a previsão de repressão ao abuso do poder

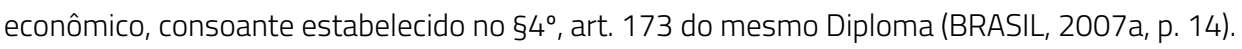




\section{PROPOSIÇÕES PARA O FORTALECIMENTO DO TURISMO DE BASE LOCAL}

Avaliar o potencial de desenvolvimento turístico de uma localidade constitui parte essencial do planejamento estratégico. Contudo, embora se reconheça a necessidade de estudos sistemáticos sobre a rentabilidade de determinados recursos turísticos, poucos foram os que avançaram na construção de referenciais teóricos consistentes para nortear tal investigação. Para auxiliar o processo de análise das atrações que podem reverter-se em condicionantes geradores potenciais de competitividade no turismo, Franscisco Leno Cerro, em um estudo sobre o Canal de Castilla, ressalta a importância do inventário dos recursos e avaliação como ferramentas imprescindiveis à tomada de decisões dentro do contexto de planificação turística, ao propor distinção entre recursos turísticos atuais e potenciais, tomando como parâmetro seu grau de integração no mercado turístico regional, nacional ou internacional (ALMEIDA, 2009, p. 542-543; CERRO, 1992, p. 53; SOARES; CARDOZO, 2012, p. 173).

A maior parte dos métodos de avaliação do potencial turístico de uma determinada localidade focaliza a análise nos recursos, equipamentos e serviços vinculados a um destino. No entanto, como sugere Marcelo Vilela de Almeida, urge-se atribuir igual importância a outros fatores como a infraestrutura de apoio turístico, isto é, obras e instalações tais como o sistema de transportes, de comunicações, serviços urbanos (água, luz, esgoto, limpeza pública) etc., bem como o elemento normativo-institucional, o qual consiste de organizações oficiais e não-governamentais responsáveis pelo planejamento e gestão pública do turismo em nível local. Por fim, é digno de menção a planificação participativa, que exprime os níveis de envolvimento e aceitação da sociedade nos processos de planejamento e/ou desenvolvimento turístico da comunidade (EMPRESA BRASILEIRA DE TURISMO, 1984, p. 8; ALMEIDA, 2009, p. 549-550).

De acordo com Licínio Cunha, os atrativos turísticos baseiam-se fundamentalmente na natureza, na história e na cultura, mas são os elementos ou os fatores naturais que, principalmente, originam a estruturação e organização da maior parte dos destinos turísticos (CUNHA, 2008, p. 22). Um exemplo disso localiza-se no balneário da Barra do Jucu, Vila Velha, Espírito Santo. Além do sublime encanto de sua orla, composta pela Praia do Barrão, Praia da Concha, Praia da Barrinha e Praia dos Recifes, a Barra conta com exuberante ecossistema que reúne imensurável diversidade biológica, em virtude de aí desembocar 
o Rio Jucu. ${ }^{18} \mathrm{~A}$ antiga vila de pescadores constitui, outrossim, importante ponto de parada na rota dos Passos de Anchieta. ${ }^{19}$ Admirada por suas tradições religiosas e folclóricas, a Barra é considerada também um núcleo de emanação da prática do Congo, ritmo musical que engloba instrumentos, vestuário e dança, sendo um elemento de caracterização cultural do estado.

No entanto, apesar de toda a sua propensão para o turismo, o potencial da Barra não tem sido convenientemente aproveitado devido à concorrência de diversos fatores. A título de exemplo, ressalta-se o desconhecimento de grande parte da população local acerca dos benefícios oriundos do fomento a esta atividade. Como exposto acima, o turismo sustentável implica outorgar à sociedade participação ativa no processo de mudanças institucionais e infraestruturais que tenha por finalidade o desenvolvimento do turismo, delegando-Ihe inclusive a incumbência de cuidar da conservação do patrimônio material local. Durante as atividades de campo, observou-se que, sobretudo, nos finais de semana, muitas pessoas não-residentes na Barra frequentam o balneário e, devido à fragilidade dos valores sociais expressos no comportamento de alguns visitantes, tem-se conspirado não apenas contra a preservação do meio

\footnotetext{
${ }^{18} \mathrm{O}$ rio Jucu é formado pelos afluentes de dois grandes braços. O rio Jucu Braço Norte nasce na região serrana do município de Domingos Martins, em cotas altimétricas de aproximadamente $1200 \mathrm{~m}$ acima no nível do mar, próximo ao Parque Estadual de Pedra Azul, local de grande relevância turística para o Estado. Seu curso se desenvolve numa extensão aproximada de 168 km, até desaguar no oceano Atlântico, mais especificamente, no lugar que recebe seu nome. De sua extensão total, cerca de 123 km compreendem o trecho conhecido como Braço Norte, enquanto os $45 \mathrm{~km}$ restantes correspondem ao trecho do rio Jucu, desde a confluência do Braço Sul até a foz, cortando os municípios de Marechal Floriano, Viana e Domingos Martins. Trata-se não apenas de importante reserva hídrica, sendo responsável por grande parte da geração de energia elétrica, irrigação de lavouras, pesca e abastecimento de água da região, mas também de valioso manancial de riqueza histórica, já que por seu intermédio realizou-se o desbravamento do interior (DEINA, 2013, p. 71-72).

${ }^{19}$ Os Passos de Anchieta é o nome do roteiro que reconstitui a trilha habitualmente percorrida pelo Padre Anchieta nos seus deslocamentos da Vila de Rerigtiba, hoje cidade de Anchieta, à Vila de Nossa Senhora da Vitória, onde cuidava do Colégio de São Tiago, na atualidade Palácio Anchieta, sede do governo estadual. Atualmente, o roteiro denominado "Passos de Anchieta" constitui um dos mais importantes atrativos do turismo religioso brasileiro, inserindo Vila Velha na rota nacional e internacional desse segmento, capaz de reunir milhares de pessoas provenientes de países como Argentina, Chile, Portugal, Espanha etc., bem como dos estados de Minas Gerais, São Paulo, Goiás, Bahia, entre outros. O percurso tem início na Prainha (local de origem da colonização do solo espírito santense), contorna o Morro do Moreno e segue pela Praia do Ribeiro em direção à orla da cidade. Os andarilhos continuam a caminhada passando pelas Praias da Costa, Itapuã e Itaparica, até chegar à Barra do Jucu, quando são percorridos em média 25 quilômetros. Após pernoitar na Barra do Jucu, eles caminham em direção à praia de Ponta da Fruta, perpassando por Guarapari, até chegar ao Santuário Nacional São José de Anchieta. Para mais informações, consultar o site da Associação Brasileira dos Amigos dos Passos de Anchieta (ABAPA), Disponível em: <http://www.abapa.org. br/interna.php?pg=ospassos, ou o site da Prefeitura Municipal de Vila Velha, Disponivel em: <http://www.vilavelha.es.gov.b r/ noticias/2018/05/passos-de-anchieta-vila-velhana-rota-do-turismo-religioso-20777.
} 
ambiente, mas também contra as boas práticas do espírito objetivo, sendo, pois, motivo de reprovação da parte dos moradores.

Outro fator a inibir o turismo no local relaciona-se à situação de vulnerabilidade a que se expõe o transeunte quando da fruição da experiência turística. $O$ sentimento de insegurança que tem aumentado nos últimos anos pode ser apontado como principal causa da suspensão por tempo indeterminado da Porca da Quarta, um dos blocos mais tradicionais do estado e uma das maiores atrações do carnaval espírito-santense, com mais de vinte cinco anos de existência, capaz de reunir milhares de pessoas. Em linhas gerais, a Porca da Quarta traz o desfile de uma leitoa com seus filhotes, que percorrem em carros alegóricos as ruas do bairro na manhã de quarta de Cinzas. As maiores atrações são o Porco Dentinho e a família formada pela Porca-Mãe, Vovô Jali, o Porco Dentão e a Porca da Quarta. Depois do desfile, a folia encerra com delicioso churrasco suíno servido pelos organizadores. Segundo Evandro Bregas, um dos idealizadores do grupo de foliões, a falta de policiamento, associado ao iminente perigo de confusão, são os responsáveis pela supressão dos festejos. O cancelamento deste representativo evento, entretanto, tem afetado particularmente os prestadores de serviços turísticos, como pousadas e restaurantes, bem como os estabelecimentos comerciais locais, que sofrem o efeito da redução dos turistas e visitantes à localidade.

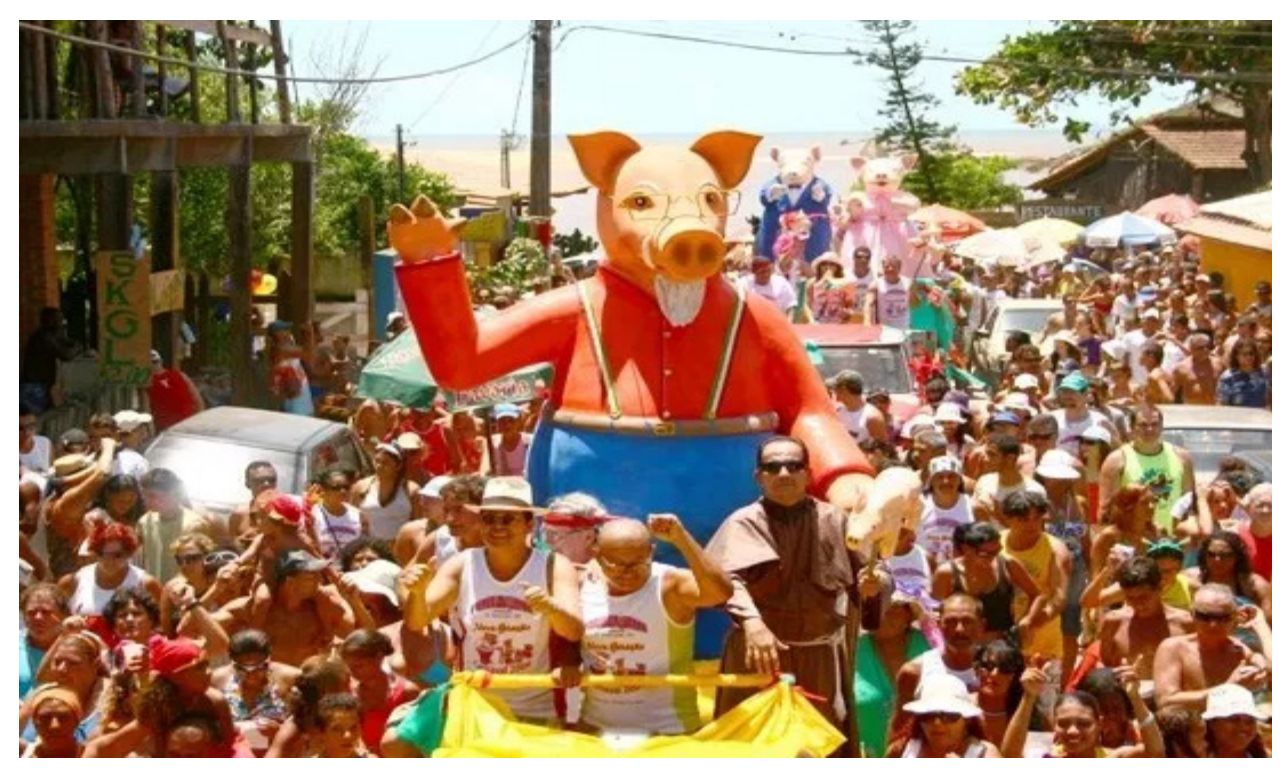

Fonte: barradojucu.com 
Para definir as dimensões relativas aos atrativos turísticos, equipamentos e serviços e infraestrutura de apoio turístico, utilizou-se como parâmetro, com as devidas ressalvas, a metodologia de inventário da oferta turística proposta pelo Ministério do Turismo. Tal procedimento objetiva conhecer as características e a extensão da oferta; o que necessita ser melhorado ou aperfeiçoado; e quais as iniciativas que devem ser tomadas para promover o desenvolvimento do turismo de modo mais competitivo e sustentável. Seu intuito é produzir um material consistente e útil para embasar as ações de planejamento, gestão, promoção e incentivo à comercialização do turismo em âmbito municipal, regional, estadual e nacional, disponibilizando, aos planejadores, gestores e visitantes, informações confiáveis e atuais (MINISTÉRIO DO TURISMO, 2011, p. 20).

Durante a pesquisa de campo, buscou-se a princípio avaliar (i) as instalações públicas e privadas, que devem proporcionar bem-estar aos residentes e visitantes, tais como sistema de transportes, de saúde, de comunicação, de abastecimento de água, de energia e tantas outras estruturas básicas e facilidades existentes para fins turísticos, bem como (ii) os estabelecimentos e prestadores de serviços que dão condições para que o visitante tenha uma boa estada: hospedagem, alimentação, diversão, transporte, agenciamento etc. Por fim, considerou-se os atrativos turísticos, como elementos da natureza, da cultura e da sociedade - lugares, acontecimentos, objetos, pessoas, ações - que motivam alguém a sair do seu local de residência para conhecê-los ou vivenciá-los (MINISTÉRIO DO TURISMO, 2011, p. 20-21). Constatou-se que a falta de planejamento turístico se manifesta não apenas na ausência de um roteiro para os turistas, mas também na inexistência de uma infraestrutura voltada, por exemplo, para atender as exigências de pessoas portadores de limitação motora ou outras necessidades especiais, situação que, somada à débil oferta de serviços básicos, como bancos, supermercados, postos de saúde etc., concorre no sentido de inibir a atividade turística.

Contudo, não obstante o cenário de descaso que grassa no lugar, é possível remediar estes problemas. O primeiro passo para implementar o turismo de forma duradoura deve ser dado no sentido de elaborar o planejamento setorial, tendo em conta o trabalho coletivo e a participação direta da comunidade local, pois sem um amplo esforço de coordenação da parte do setor público as chances de sucesso se reduzem grandemente. De fato, o êxito de um programa ou projeto depende de planejamento, de executores eficientes e da construção de uma base de dados atualizada e confiável para um eficaz monitoramento e avaliação (BEZERRA, 2006, p. 351; BRASIL, 2010a, p. 20).

Uma questão fundamental a esse respeito é definir o que se tem a oferecer, o que implica transformar recursos em oportunidades de negócio, pois é a partir da análise da oferta que se pode traçar o perfil do turista que se deseja atrair. Na literatura oficial do Ministério do Turismo, lê-se que "os produtos devem ser oferecidos de forma a atender as necessidades e demandas específicas de cada cliente, pois o mesmo 
produto pode atender as demandas de um perfil de cliente e ser inadequado para outros segmentos". Em Segmentação do Turismo e o Mercado (2010), evidencia-se não ser adequado que uma localidade dependa de um único produto, principalmente se ele for sazonal, como é o caso do turismo de sol e praia. Em vez disso, é mais recomendável oferecer um cardápio variado de produtos atrelados às modalidades de turismo cultural e gastronômico, que possam, outrossim, mediante eventos locais vinculados a datas comemorativas, atender os visitantes em diferentes períodos do ano (BRASIL, 2010a, p. 35; 2010b, p. 9).

O Brasil possui um patrimônio cultural diversificado e plural. Sua pluralidade e diversidade cultural representam, para o turismo, a oportunidade de estruturação de novos produtos turísticos, com o consequente aumento do fluxo de turistas e geração de emprego (BRASIL, 2010b, p. 11). O Turismo Cultural, nesse caso, constitui um importante segmento turístico, que funda sua existência na motivação do turista de se deslocar especialmente com a finalidade de vivenciar aspectos e situações que são peculiares da nossa cultura. ${ }^{20} \mathrm{~A}$ Barra do Jucu, nesse particular, se distingue como celeiro cultural graças à riqueza de seu folclore expresso no Congo, gênero musical de raiz africana, originário genuinamente das regiões litorâneas do Espírito Santo, e mundialmente conhecido graças ao grupo musical Casaca. ${ }^{21}$ Festividades como a Puxada de Mastro, evento em que é fincado um mastro em frente à Igreja de Nossa Senhora da Glória, em 27 de dezembro, quando da festa de São Benedito, e retirado em 20 de Janeiro, constituem tanto atividade cultural, quanto profícua oportunidade para acionar diversos setores da economia local, como o artesanato, o comércio e outras operações produtivas. ${ }^{22}$

\footnotetext{
20 Hoje em dia, existe uma tendência crescente de viagens de Turismo Cultural por destinos caracterizados pela cultura viva presente no modo de vida das comunidades, seus saberes e fazeres, suas manifestações tradicionais e folclóricas, expressas principalmente na gastronomia típica, nas festas e celebrações populares, nas lendas, histórias locais, nos produtos artesanais etc. Outra vantagem do Turismo Cultural é que ele não depende tanto das condições climáticas, como o Turismo de Sol e Praia ou outros segmentos cujas atividades são realizadas integralmente ao ar livre. Por isso, as viagens desse segmento podem acontecer ao longo de todo ano, sem grandes variações no fluxo de visitantes, sendo uma alternativa para a redução da sazonalidade nos destinos (BRASIL, 2010b, p. 37-54).

${ }^{21}$ A banda Casaca é um grupo musical procedente da Barra do Jucu, formado no início do ano de 2000, com ex-integrantes do grupo Kalango-Congo. É deles a canção que despertou o robô da Nasa, Spirit, em Marte, no dia 11 de janeiro de 2004. Disponível em: <https://www.youtube.com/watch?v=1V6zPQLsQJI.

22 Diz-se que no século XIX, um navio negreiro naufragou na costa do Espírito Santo. Alguns sobreviventes chegaram à praia agarrados em um mastro, que flutuou. Deste então, em reverência a São Benedito, todos os anos na Barra do Jucu homenagens são feitas sob a denominação de "Fincada de Mastro".
} 
Figura 2 - População carregando o mastro em homenagem à São Benedito

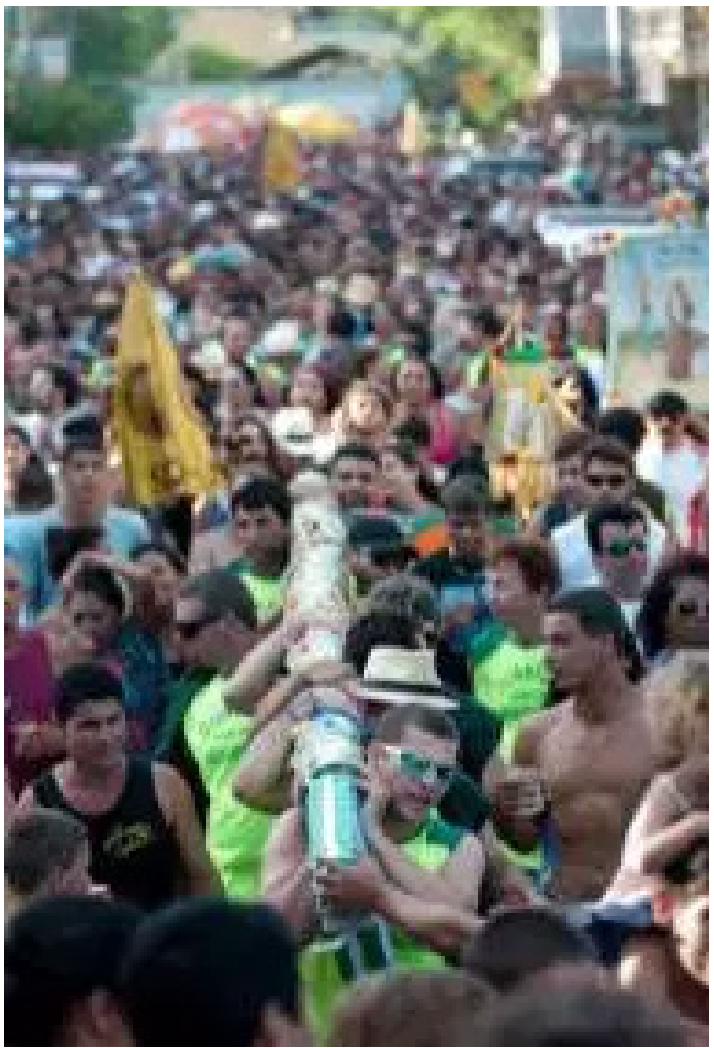

Fonte: barradojucu.com

Um outro importante elemento do patrimônio cultural local que pode compor a oferta turística encontra-se em sua gastronomia, um tipo de arte que, embora acompanhe a dinâmica da humanidade, expressa o espírito de um povo, uma região ou localidade. O turismo gastronômico se afigura, pois, como um segmento que busca, na culinária típica de um lugar, um atrativo adicional, ao oferecer ao turista a oportunidade de compartilhar sabores, saberes e costumes que acompanham o alimento desde seu estado in natura até sua degustação à mesa. O prazer proporcionado pelo gosto, em muitos casos, constitui experiência sensorial única e indelével, o que representa uma vantagem competitiva em favor do desenvolvimento turístico (BRASIL, 2010b, p. 31; GARCIA; ZOTTIS; BONHO, 2015, p. 69).

No Espírito Santo, a moqueca está presente no cardápio de cerca de 85\% dos restaurantes situados na região litorânea, sendo considerado valioso insumo para o comércio e, ao mesmo tempo, permanente elemento de identidade local. Na Barra do Jucu, o prato mais pedido é, sem dúvida, a moqueca capixaba, 
uma das iguarias mais famosas do Brasil. Atrelado a esta deliciosa moqueca, que somente assume seu gosto único se preparado em panelas de barro, está a riquíssima tradição das paneleiras de barro, legado cultural dos índios Guarani, e passado de geração a geração, definindo não apenas uma rede de significados presente num específico comportamento social, mas também criando meios de vida para centenas de mulheres e homens envolvidos no preparo deste utensilio (MARQUES; CALOTI, 2013, p. 166-167).

Infelizmente, um grupo seleto de pessoas identifica com clareza o imensurável potencial de riqueza material, cultural e social da Barra do Jucu. Tal circunstância reforça a ideia de que o Estado, personificado na pessoa jurídica do agente público ou político, em observância à Lei 11.771/08, e todo o aparato legal colocado à sua disposição, deve ter participação ativa na promoção de um lugar, a fim de tornar do conhecimento da sociedade suas belezas e potencial turístico. O marketing ocupa posto de destaque nesse caso, pois os jornais e as mídias em geral são protagonistas na difusão não somente de informações, mas também representações, comportamentos, desejos etc. Uma outra estratégia plausível a esse respeito é perscrutar os anseios das pessoas e, a partir disso, analisar oportunidades, selecionar os consumidoresalvo e ponderar a forma mais profícua de ofertar-lhes os bens e serviços, com vistas a satisfazer suas aspirações.

Posto isto, convém conhecer em profundidade o perfil do turista, sua faixa etária, poder de compra, condições sociais, escolaridade, ocupação, estado civil, motivações etc. Tais variáveis especificam as decisões a serem adotadas em relação ao mercado; ao tipo de produto; aos preços e às atividades de promoção e comercialização etc. (BEZERRA, 2004, p. 142). Por outro lado, como ideias podem ser melhor identificadas se expressas em uma marca, talvez seja oportuno frisar as características distintivas da Barra, ressaltando-Ihe os elementos tanto natural, quanto cultural e gastronômico.

\section{CONSIDERAÇÕES FINAIS}

O artigo colocou o turismo em perspectiva histórica, a fim de mostrar como esta atividade vem se modificando ao longo do tempo, ao incorporar em seu bojo não apenas demandas econômicas, mas também questões de ordem social, cultural, política e ambiental. Destacou-se, outrossim, que a geração e distribuição de renda, inerentes à atividade turística, favorecem o desenvolvimento da economia nacional, ao passo que a modalidade de turismo internacional tende a ser mais significativa em regiões relativamente próximas aos grandes blocos emissores. Nesse sentido, visto que o Brasil, por uma razão espacial, distancia-se destes blocos, convém direcionar seus esforços não somente para atrair turistas estrangeiros - não obstante a importância em manter crescentes as reservas cambiais -, sendo igualmente oportuno e profícuo o incentivo ao turismo doméstico. 
Deu-se ênfase às experiências bem-sucedidas de países em que o Estado atuou de forma proficiente na condução da política de turismo, bem como aos preceitos extraídos do Plano Nacional de Turismo, para reforçar a ideia de que são imprescindiveis o planejamento setorial e a participação ativa do governo, do setor terciário e dos segmentos da sociedade para consumação cabal dos objetivos ali discriminados. Analisou-se, por fim, o caso da Barra do Jucu, ressaltando suas vantagens competitivas tanto no que concerne a sua beleza natural e biodiversidade, quanto outros atrativos relativos a suas exuberantes cultura e gastronomia locais. Apesar das limitações do autor, buscou-se propor medidas para reverter a situação de descaso aí latente, de modo que a morosidade daqueles que deveriam cuidar do bem turístico não deixe que esse nicho caia no abandono.

\section{REFERÊNCIAS}

AGUIAR, Leila B. Estado, Turismo, Cultura e Desenvolvimento: organização empresarial e a construção de um consenso sobre a importância do turismo para o Brasil. VI Simpósio Nacional Estado e Poder: Cultura. p. 1-12, 2010. Disponivel em: <http://www.historia.uff.br/estadoepoder/6snepc/GT1/GT1-LEILA. pdf.>. Acesso em: 24/11/2018.

ALMEIDA, Marcelo V. Matriz da Avaliação do Potencial Turístico de Localidades Receptoras. Turismo em Análise. Vol. 20, n. 3, p. 541-561, 2009.

AKTAR, A.; SADEKIN, N.; SAHA, S.K. The Relationship between Tourist Arrival and Foreign Exchage Earnings: The Case for Bangladesh. Mediterranean Journal of Social Sciences. Vol. 5, n. 16, p. 162-165, 2014.

ANDRADE, José Vicente de. Turismo: fundamentos e dimensões. Ática: São Paulo, 2000.

BALAIA, Alina E.; PETRUSCU, Raluca M. The involvement of the public and private sector - Elements wich influence on Travel \& Tourism demand during the crisis period. Tourism and Hospitality Management, Vol. 17, No. 2, pp. 217-230, 2011.

BEZERRA, Márcia M. Estratégias de desenvolvimento do turismo: em busca de uma tipologia. Economia e Sociedade, Vol. 15, n. 2, p. 347-374, 2006.

BRASIL, Ministério do Turismo. Inventário da Oferta Turística: estratégia de gestão. Brasília, 2004.

BRASIL, Ministério do Turismo. Programa de Regionalização do Turismo - Roteiros do Brasil: Módulo Operacional 8 - Promoção e Apoio à Comercialização. Brasília, 2007b. 
BRASIL. Ministério do Turismo. Estudos da competitividade do turismo brasileiro. Brasília, 2007a.

BRASIL. Ministério do Turismo. Segmentação do turismo e o mercado. Brasília, 2010a.

BRASIL. Ministério do Turismo. Turismo Cultural: orientações básicas. Brasília, 2010b.

BRASIL. Ministério do Turismo. Inventário da Oferta Turística. Brasília, 2011.

BRASIL, Ministério do Turismo. Plano Nacional de Turismo 2018-2022: mais renda e emprego para o Brasil. Brasília, 2018.

CERRO, Franscisco L. La evaluacion del potencial turístico em un proceso de planificacion: el canal Castilla. Estudios Turísticos, n. 116, p. 49-85, 1992.

CUNHA, Licínio. Avaliação do Potencial Turístico. Journal of Tourism Studies, Vol. 1, n.1, p. 21-40, 2008.

DEINA, Miquelina A. Alterações hidrogeomorfológicas no baixo curso do rio Jucu (ES). 2013. 186f. Dissertação (Mestrado em Geografia) - Programa de PósGraduação em Geografia, Universidade Federal do Espírito Santo, Vitória, 2013.

EMPRESA BRASILEIRA DE TURISMO. 1984. Metodologia do inventário da oferta turística. Rio de Janeiro.

FERREIRA, Victor H. Teoria Geral do Turismo. Palhoça: UnisulVirtual, 2007.

GARCIA, Roslaine K; ZOTTIS, Alexandra M.; BONHO, Daniel V. A Gastronomia e seu uso turístico: A contribuição do Projeto de Extensão "Turismo e Gastronomia": Unindo sabores e saberes para a valorização do patrimônio cultural imaterial. Gestão e Desenvolvimento, Vol. XII, n. 2, p. 67-82, 2015.

HANAI, Frederico Y. Desenvolvimento sustentável e sustentabilidade do turismo: conceitos, reflexões e perspectivas. Revista Brasileira de Gestão e Desenvolvimento Regional. Vol. 8, n. 1, p. 198-231, 2012.

KADT, Emanuel de. Tourism - Passaport to Development? Perspective on the Social and Cultural Effects of Tourism in Developing Countries. Washington: Unesco and the International Bank, 1979.

LICKORISH, Leonard; JENKINS, Carson. An Introduction to Tourism. Oxford: Butterworth-Heinemann, 1997.

MAMEDE, Gladston. Direito do Turismo - Legislação específica aplicada. São Paulo: Atlas, 2004.

MARQUES, Marcelo de Souza; CALOTI, Vinícius de Aguiar. As Paneleiras de Goiabeiras e a dinâmica da Cultura. Sociologia, Revista da Faculdade de Letras da Universidade do Porto, Vol. XXVI, p. 163-185, 2013. 
MÜLLER, Dalila; HALLAL, Dalila R.; RAMOS, Maria G.; GARCIA, Tania E. O despertar do Turismo no Brasil: A década de 1970. Book of Proceedings, Vol. I - International Conference on Tourism \& Management Studies - , p. 692-700, 2011.

NAWAZ, Muhammad A.; HASSAN, Sallahuddin. Investment and Tourism: Insights from the literature. International Journal of Economic Perspectives, Vol. 10, n. 4, p. 581-590, 2016.

RABBANY, Ghulan; AFRIN, Sharmin; RAHMAN, Airin; ISLAN, Faijul; HOQUE, Fazlul. Environment, Energy and Power Research. Vol. 1, No 7, Setember, p. 117-130, 2013.

ROMITA, Tullio. Argomenti di Sociologia del Turismo. Working Papers di Sociologia e Scienza della Politica, Università di Messina e Università della Calabria, n. 78, p. 1-19, 2000.

SANTOS, Marivan T. Fundamentos de turismo e hospitalidade. Manaus: Centro de Educação Tecnológica do Amazonas, 2010.

SAVELLI, Asterio di. I percorsi della Sociologia del Turismo in Italia. Rivista di Scienza del Turismo, Vol. 1, p. 5-42, 2011.

SILVA, Kely M. A importância do Turismo para o desenvolvimento econômico do Estado do Espírito

Santo. 2004. 65f. Monografia. (Centro de Ciências Jurídicas e Econômicas) - Departamento de Economia, Universidade Federal do Espírito Santo, Vitória.

SOARES, Joélcio G.; CARDOZO, Poliana Fabíula. Metodologia para aferimento de potencialidade turística: um estudo de caso. Revista Espaço Acadêmico, n. 128, p. 171-179, 2012.

TAMBAKTIS, Tom. Le secteur touristique et les enjeux de durabilité dans les Pays en Développement. Quelle combinaison vertueuse?. 2016. 130f. (Dissertação) Master 2 Économie appliquée Spécialité Développement Territorial, Parcours Aide au Développement Faculté d'économie et de gestion, Marseille Université, Marseille. 